Molecules 2001, 6, 988-995

molecules

ISSN 1420-3049

http://www.mdpi.org

\title{
Novel Chiral Switching Ligands for Enantioselective Asymmetric Reductions of Prochiral Ketones
}

\author{
S. Narasimhan ${ }^{1, *}$, S. Swarnalakshmi ${ }^{2}$, R. Balakumar ${ }^{1}$ and S. Velmathi ${ }^{1}$ \\ ${ }^{1}$ Centre for Natural Products, SPIC Science Foundation, Guindy, Chennai 600 032, India. \\ ${ }^{2}$ Department of Chemistry, Guru Nanak College, Velachery, Chennai 600 042, India. \\ * Author to whom correspondence should be addressed; e-mail: narasim3_@ hotmail.com
}

Received: 14 May 2001; in revised form 1 November 2001 / Accepted: 5 November 2001 / Published: 30 November 2001

\begin{abstract}
The newly developed chiral ligands $\mathbf{1}$ and $\mathbf{4}$ show opposite enantioselectivity in the asymmetric reduction of prochiral ketones resulting in the production of either enantiomer depending on the metal complex with high enantiomeric excess.
\end{abstract}

Keywords: Oxazaborolidines, dihydrooxazaborins, oxazaaluminium complex, Chiral switch.

\section{Introduction}

The asymmetric reduction of prochiral ketones with simple chiral borane complexes resulted in disappointingly low ee $(1.5-3.5 \%)$ [1]. However, the $\mathrm{N}_{-} \mathrm{BH}_{3}$ coordinated oxazaborolidines pioneered by Itsuno [2] and developed by Corey [3] gave excellent results. The success of oxazaborolidines could be due to the operation of two center catalysis enumerated by Helmchen et al. involving a Lewis acidic center and a Lewis basic center [4]. Obviously the absence of such two centered reaction in the case of amino acid ester complex could be the reason for the low ee. Hence we opted to design compounds in which the ester moiety of the amino acid is retained and construct the oxazaborolidine ring as shown below (Figure 1). 
Figure 1

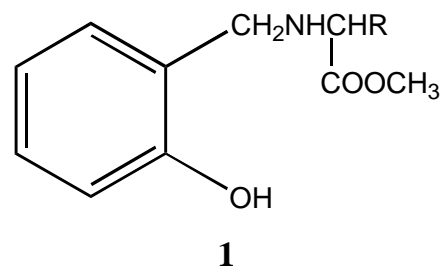

Where R=iso-propyl (1a), iso-butyl (1b), sec-butyl (1c)

Indeed we found that these ligands can induce chiral switching in the reduction of prochiral ketones, which is described here. The chiral ligands (1a-c) were synthesized using salicylaldehyde and various amino acid esters as starting materials through the formation of the corresponding imine esters and selective reduction of the imine esters to amine esters using tetrabutylammonium borohydride [5,6]. Interestingly in all these chiral ligands, the two benzylic protons remain stereochemically non equivalent as shown by two doublets at $\delta=4.1 \mathrm{ppm}$ and $\delta=3.6 \mathrm{ppm}, \mathrm{J}=13.5 \mathrm{~Hz}$ in their ${ }^{1} \mathrm{H}-\mathrm{NMR}$ spectra. This can be attributed to the conformational locking achieved through hydrogen bonding as seen below (Figure 2).

\section{Figure 2}

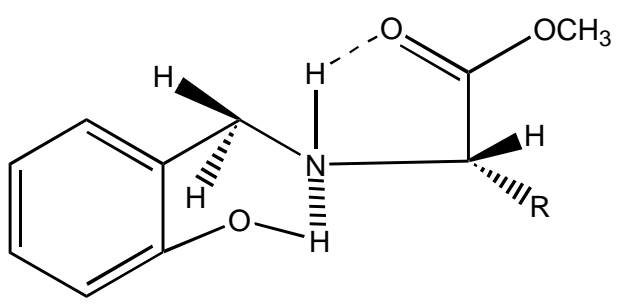

The corresponding dihydrooxazaborins 2 can be prepared by the method of Brown and Corey [7]. The reaction resulted in the initial liberation of hydrogen at room temperature. Thus, $1 \mathrm{mmol}$ of 1 liberates 2 mmol of $\mathrm{H}_{2}$ upon treatment with $1 \mathrm{mmol}$ of borane in THF at room temperature. After the liberation of $\mathrm{H}_{2}$ ceased, the reaction mixture was refluxed for $1.5 \mathrm{~h}$ and the formation of 2 was confirmed using ${ }^{11} \mathrm{~B}-\mathrm{NMR}$ $(\delta-24 p p m)$.

\section{Scheme 1}<smiles>[2H][C@H](C(=O)OC)N1Cc2ccc(C(F)(F)F)cc2OB1P</smiles>

Where R=iso-propyl (a), iso-butyl (b), sec-butyl (c) 
The chiral reducing agents 3 were prepared in situ by refluxing 2 and $\mathrm{BH}_{3} / \mathrm{THF}$ in a 1:1 ratio for one hour. Interestingly, the ester group remained intact as evidenced by the peak at $1735 \mathrm{~cm}^{-1}$ in the IR spectrum. Also, the ligand isolated after hydrolysis did not exhibit any change in the functional groups.

\section{Results and Discussion}

Reduction of acetophenone with these chiral reducing agents 3a-3c was representative. The reductions were instantaneous resulting in optically active 1-phenyl ethanol. Interestingly, the dihydrooxazaborins derived from valine methyl ester, 3a showed good enantioselectivity (ee of $75 \%$ of the R -enantiomer). However, $\mathbf{3 b}$ and $\mathbf{3 c}$ showed poor to moderate enantioselectivity (15-55\%) (Table 1, entries 1-3). The instantaneous reduction indicates that the reduction is effected by nitrogen-coordinated borane $\left(\mathrm{N}-\mathrm{BH}_{3}\right)$, which is more nucleophilic. The predominant formation of the $R$-enantiomer may be due to the more selective transfer of hydride from the reagent to the $S i$ face of the ketone. Hence, Corey's mechanism involving the hydride transfer from the reagent to the $S i$ face of the ketone via the formation of a six membered cyclic transition state is expected for the reduction. However, the lower observed ee for the reduction may be due to the competition of the carbonyl group of the ketone for coordination with boron from ester carbonyl of the reagent (Figure 3).

\section{Figure 3}
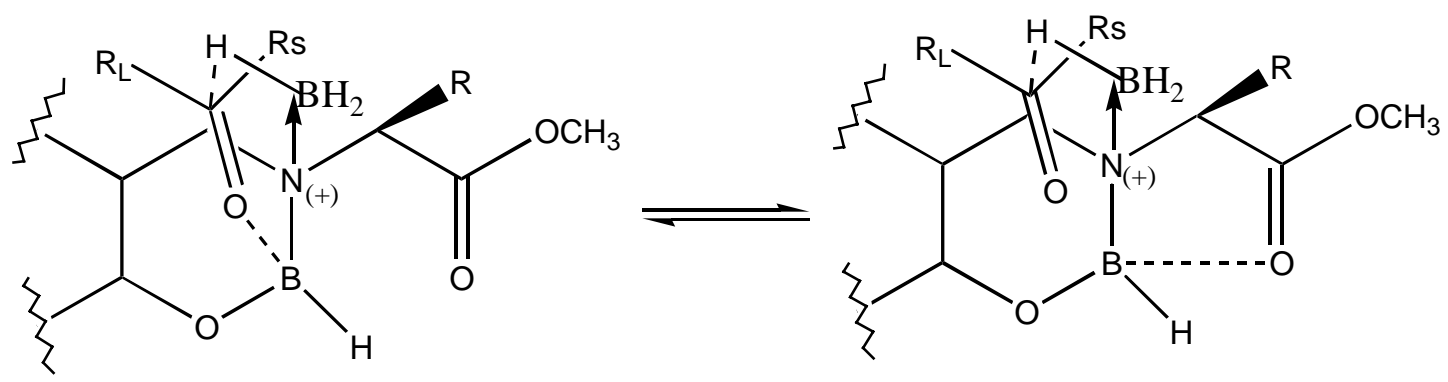

The variation of $e e$ with respect to the nature of alkyl group of the dihydrooxazaborin may be due to the different steric influence offered by the $R$ group towards stereo selective reduction. The reductions were also carried out at lower temperatures to find out if ee could be improved. But, when the reactions were performed at $0^{\circ} \mathrm{C}$, the ee was decreased which could be due to the formation of a dimer of dihydrooxazaborin as suggested by Corey [8]. Moreover, at low temperature $\left(0^{\circ} \mathrm{C}\right)$, the equilibrium could be shifted more towards the intramolecular ester carbonyl coordination with boron resulting in a less selective reduction of ketone accounting for lesser ee. At room temperature, $\left(25^{\circ} \mathrm{C}\right)$ the equilibrium would be shifted more towards the ketone carbonyl coordination with boron, which helps in more selective reduction of ketone and is thus responsible for fairly high ee. The results are listed in Table 1. 
Table 1: Reduction of acetophenone using dihydrooxazaborins at different temperatures

\begin{tabular}{|c|c|c|c|c|c|}
\hline S.No & Chiral reducing agent & Temp & {$[\alpha]_{D}^{23^{\circ}} \mathrm{c}=5\left(\mathrm{CHCl}_{3}\right)[9]$} & $e e(\%)$ & Yield (\%) \\
\hline 1 & iso-propyl (3a) & $30^{\circ} \mathrm{C}$ & $31.5(+42)^{*}$ & 75 & 99 \\
\hline 2 & iso-butyl (3b) & $30^{\circ} \mathrm{C}$ & 6.3 & 15 & 92 \\
\hline 3 & sec-butyl (3c) & $30^{\circ} \mathrm{C}$ & 23.1 & 55 & 90 \\
\hline 4 & iso-propyl (3a) & $0^{\circ} \mathrm{C}$ & 6.3 & 15 & 94 \\
\hline 5 & sec-butyl (3c) & $0^{\circ} \mathrm{C}$ & 4.2 & 10 & 93 \\
\hline
\end{tabular}

$*$ Value in parenthesis indicates the reported $[\alpha]_{\mathrm{D}}^{23^{\circ}}$ value

The results suggest that if the equilibrium is shifted more towards the coordination of the ketone carbonyl and the boron, the ee can be enhanced. This can be achieved by the addition of hard acids such as lithium salts, which can disrupt the coordination between ester and boron without affecting the conformational locking (Figure 4).

\section{Figure 4}

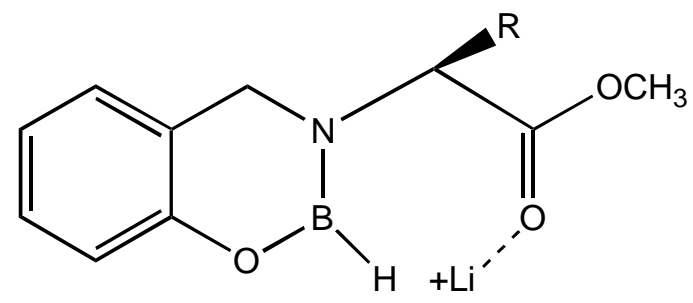

Hence, reductions were carried out with chiral reducing agents derived from valine in presence of stoichiometric quantities of lithium salts. Interestingly, when $\mathrm{LiBr}$ was added to a freshly prepared solution of N-borane coordinated dihydrooxazaborin, and stirred for $15 \mathrm{~min}$. at room temperature followed by the addition of $5 \mathrm{mmol}$ of acetophenone increased the $e e$ of the alcohol to $90 \%$. The results are presented in Table 2.

Table 2: Reduction of ketones in presence of lithium salts at room temperature $\left(30^{\circ} \mathrm{C}\right)$

\begin{tabular}{|c|c|c|c|c|c|}
\hline Salts & Ketones & Product & $\begin{array}{c}{\left[\boldsymbol{\alpha}_{\mathbf{D}}{ }^{\mathbf{2 3}^{\mathbf{0}} \mathbf{c = 5}}\right.} \\
\left(\mathbf{C H C l}_{\mathbf{3}}\right)[9]\end{array}$ & $\begin{array}{c}\boldsymbol{e e} \\
(\boldsymbol{\%})\end{array}$ & $\begin{array}{c}\text { Yield } \\
(\boldsymbol{\%})\end{array}$ \\
\hline $\mathrm{LiBr}$ & Acetophenone & 1-phenylethanol & $37.8(+42)^{\#}$ & 90 & 90 \\
$\mathrm{LiClO}_{4}$ & Acetophenone & 1-phenylethanol & 33.6 & 80 & 93 \\
$\mathrm{LiBr}$ & Phenacyl chloride & 2-chloro-1-phenylethanol & $35.7(-41.3)$ & 85 & 90 \\
\hline
\end{tabular}

${ }^{\#}$ Value in the parenthesis indicate the reported $[\alpha]_{\mathrm{D}}{ }^{23^{\circ}}$ value 
Alternatively, the coordination of boron and ester carbonyl can also be disrupted by reducing the ester moiety by forming a tridentate chiral precursor 4 [6] (Scheme 2).

\section{Scheme 2}

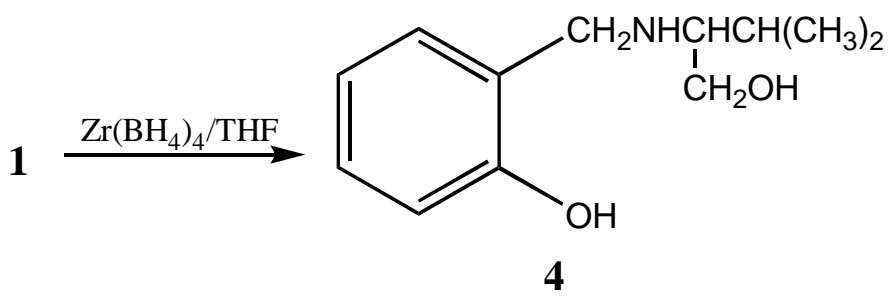

This chiral precursor with a tridentate ligand is considered to be more appropriate for asymmetric reductions than an unidentate or bidentate ligand due to the rigid complex formation,. These tridentate chiral precursors can also be utilized for the formation of heterobimetallic chiral reagent using $\mathrm{LiAlH}_{4}$ leading to the formation of chiral dioxazaluminium complex, which is another potential chiral reagent for selective reduction of ketones [10] (Scheme 3).

\section{Scheme 3}

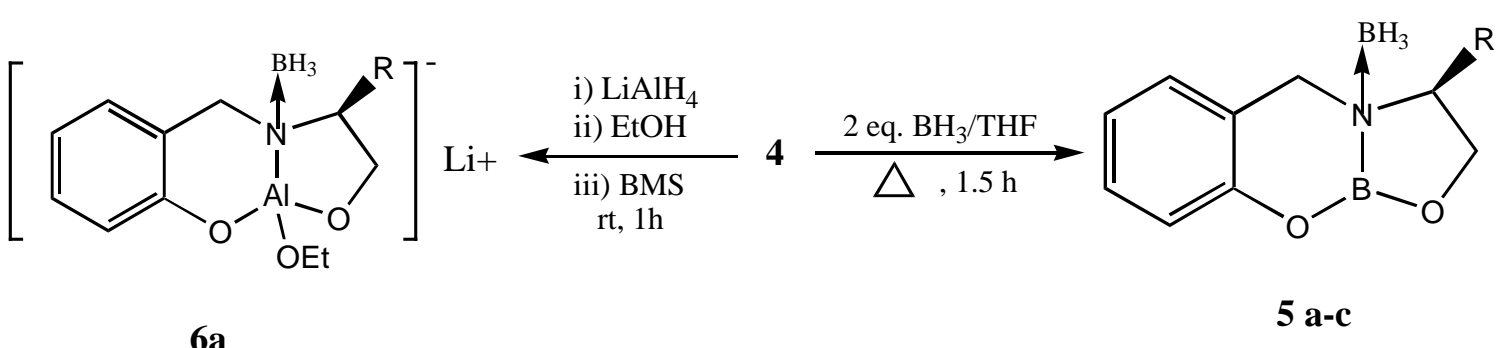

Thus, several bicyclic oxazaborolidines (5) were prepared from the amino acids valine, leucine and iso-leucine and they were studied for the reduction of prochiral ketones at room temperature (Table 3 ).

Table 3 Reduction of Acetophenone at room temperature with various bicyclic oxazaborolidines

\begin{tabular}{|c|c|c|c|}
\hline $\mathbf{R}$ & {$[\boldsymbol{\alpha}]_{\mathbf{D}} \mathbf{2 3}^{\mathbf{o}} \mathbf{c = 5}\left(\mathbf{C H C l}_{\mathbf{3}}\right)[9]$} & $\boldsymbol{e e ~}(\boldsymbol{\%})$ & Yield (\%) \\
\hline 5a iso-propyl & 37.8 & 90 & 95 \\
5b iso-butyl & 4.2 & 10 & 89 \\
5c sec-butyl & 23.1 & 55 & 90 \\
\hline
\end{tabular}

This predominant formation of the $R$ enantiomer using 5a follows Corey's mechanism involving the hydride transfer from the reagent to the $\mathrm{Si}$ face of the ketone via the formation of a six membered cyclic transition state. 
Interestingly, when the reduction was carried out with the heterobimetallic complex $6 \mathbf{a}$ the reduction proceeded with reversal of enantioselectivity albeit with lesser ee. Probably in the oxazaluminium complex the mechanism could involve the hydride transfer from the reagent to the $R e$ face of the ketone through aluminium. This could arise due to the exchange of hydride from boron to aluminium. Therefore, we prepared a complex with $\mathrm{LiAlH}_{4}$ (7a, Figure 5) without quenching the hydride and studied the asymmetric reduction of acetophenone.

\section{Figure 5}

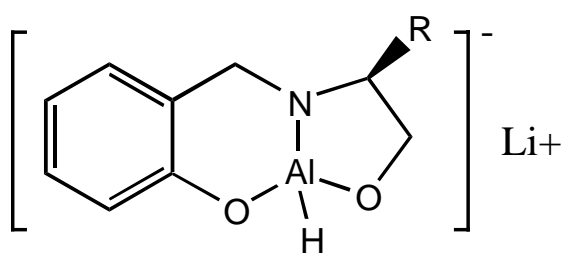

$7 \mathbf{a}$

Indeed we obtained the opposite isomer in fairly good ee. The results are given in Table 4. Binding of electrophilic carbonyl oxygen with lithium and the additional pi stacking interaction existing between the phenyl ring of acetophenone and the phenyl ring of the reagent are mainly responsible for more selective transfer of hydride from aluminium to the $R e$ face of the ketone via a six membered cyclic transition state thus accounting for the formation of $S$ - alcohol and the observed ee.

Table 4 Reduction of ketones with bicyclic oxazaborolidine and dioxazaluminium complex derived from valine

\begin{tabular}{|c|c|c|c|c|c|}
\hline Ketones & $\begin{array}{c}\text { Reagent/ } \\
\text { Temp }\end{array}$ & Product & $\begin{array}{c}\text { Yield } \\
(\boldsymbol{\%})\end{array}$ & $\begin{array}{c}\boldsymbol{e e} \\
(\boldsymbol{\%})\end{array}$ & $\begin{array}{c}{[\boldsymbol{\alpha}]_{\mathbf{D}}{ }^{\mathbf{2 3}^{\circ}}} \\
\mathbf{c = 5}\left(\mathbf{C H C l}_{\mathbf{3}}\right)[9]^{\mathrm{a}}\end{array}$ \\
\hline Acetophenone & $\mathbf{5 a} / 30^{\circ} \mathrm{C}$ & 1-phenylethanol & 95 & $90(\mathrm{R})$ & $+37.8(+42)$ \\
Phenacyl chloride & $\mathbf{5 a} / 30^{\circ} \mathrm{C}$ & 2-chloro-1-phenylethanol & 90 & $85(\mathrm{~S})$ & $+35.7(+43)$ \\
Acetophenone & $\mathbf{6 a} / 30^{\circ} \mathrm{C}$ & 1-phenylethanol & 90 & $30(\mathrm{~S})$ & $-12.6(-41.3)$ \\
Acetophenone & $\mathbf{7 a} / 0^{\circ} \mathrm{C}$ & 1-phenylethanol & 90 & $60(\mathrm{~S})$ & -24.7 \\
Phenacyl chloride & $\mathbf{7 a} / 0^{\circ} \mathrm{C}$ & 2-chloro-1-phenylethanol & 90 & $55(\mathrm{R})$ & $-26.4(-48)$ \\
\hline
\end{tabular}

${ }^{a}$ Values in the parentheses indicate the literature reported $[\alpha]_{D}{ }^{23^{\circ}}$ values

Thus, the chiral reducing agents derived from same precursor showed opposite enantioselectivity, which is a unique phenomenon. In conclusion, we have developed novel chiral reagents, which are useful in the syntheses of optically active secondary alcohols of opposite configuration depending upon the nature of the metal complex, which is not possible with other reagents. 


\section{Acknowledgements}

The authors thank Prof T.R.Govindachari for his constant support and encouragement. Dr. S.L. thanks the Department of Chemistry, GNC, for their support and S.V. thanks CSIR, New Delhi for financial assistance.

\section{Experimental}

\section{General}

The solvents and chemicals used in this work were obtained commercially and were purified using conventional methods. The NMR spectra were recorded on a BRUKER $200 \mathrm{MHz}$ instrument. Optical rotations were recorded using a Autopol polarimeter using $\mathrm{CHCl}_{3}$ as solvent at $23^{\circ} \mathrm{C}$ using the sodium Dline monochromator $(2580 \AA)$.

Preparation of dihydrooxazaborin 2: $\mathrm{BH}_{3} / \mathrm{THF}$ solution $(5 \mathrm{~mL}, 1 \mathrm{M})$ were added to $5 \mathrm{mmol}$ of the chiral precursor. The formation of $\mathbf{2}$ was monitored through hydrogen evolution by connecting the system to the gas burette. After the liberation of $\mathrm{H}_{2}$ was complete the reaction mixture was refluxed for 1 to $1.5 \mathrm{~h}$.

Reduction of acetophenone using $\mathbf{2 a}$ : $1 \mathrm{M}$ borane-THF $(5 \mathrm{mmol})$ was added at room temperature to a freshly prepared solution of $5 \mathrm{mmol}$ of dihydrooxazaborin, derived from valine methyl ester and salicylaldehyde $(5 \mathrm{~mL})$ and the resulting mixture was and stirred for $30 \mathrm{~min}$. Then acetophenone $(0.6 \mathrm{~mL}$, $5 \mathrm{mmol}$ ) was added, the mixture stirred for $10 \mathrm{~min}$ at room temperature and then quenched with methanol. The reaction mixture was extracted with hexane and the hexane extract was washed with dil. $\mathrm{HCl}$ followed by water, dried over anhydrous sodium sulphate and the solvent was removed under reduced pressure. Purification was achieved using column chromatography with hexane: ethyl acetate 98:2 as eluant to give (R)-(+)-1-phenylethanol in $99 \%$ chemical yield with $e e$ of $75 \% ;[\alpha]_{\mathrm{D}}^{23}+31.5^{\circ}$.

Reduction in the presence of lithium salts: $\mathrm{LiBr}, 0.4 \mathrm{~g}(5 \mathrm{mmol})$ in $\mathrm{THF}(5 \mathrm{~mL})$ was added to a freshly prepared solution of $\mathrm{N}$-borane coordinated dihydrooxazaborin $(5 \mathrm{mmol})$ and the mixture stirred for $15 \mathrm{~min}$. at room temperature followed by the addition of acetophenone $(0,6 \mathrm{~mL}, 5 \mathrm{mmol})$. The reaction mixture was stirred for 10min. at room temperature and the quenched with methanol. The product was extracted and purified as described above. The alcohol (R)-(+)-1-phenylethanol was obtained in $90 \%$ chemical yield and with $e e$ of $90 \%[\alpha]_{\mathrm{D}}^{23}+37.8^{\circ}$.

Preparation of bicyclic oxazaborolidine 5a: Borane-THF solution $(5 \mathrm{~mL}, 1 \mathrm{M}, 5 \mathrm{mmol})$ was added to 5 mmol of $\mathbf{4}$, and the formation of oxazaborolidine was monitored through the quantitative evolution of hydrogen by connecting the system to gas burette. After the hydrogen liberation was complete the reaction mixture was refluxed for 1 to $1.5 \mathrm{~h}$ 
Reduction of acetophenone using 5a: Borane THF solution $(5 \mathrm{~mL}, 1 \mathrm{M}, 5 \mathrm{mmol})$ was added to a freshly prepared solution of $5 \mathrm{mmol}$ of $\mathbf{5 a}$, and the mixture stirred at room temperature for $30 \mathrm{~min}$. Then acetophenone $(0.6 \mathrm{~mL}, 5 \mathrm{mmol})$ was added and stirring continued for $10 \mathrm{~min}$ at room temperature, then the reaction wasquenched with methanol. The reaction mixture was extracted with hexane and the hexane extract was washed with dil. HCL followed by water, dried over anhydrous sodium sulphate and the solvent was removed under reduced pressure. Purification is achieved using column chromatography (hexane: ethyl acetate $98: 2$ as eluant) to give $0.56 \mathrm{~g}$ of $(\mathrm{R})-(+)-1$-phenylethanol (95\% yield) with ee of $90 \%$.

Preparation of dioxazaluminium complex 7a: $\mathrm{LiAlH}_{4}(0.19 \mathrm{~g}, 5 \mathrm{mmol})$ was added to $5 \mathrm{mmol}$ of 4 in THF and the mixture was stirred at room temperature for 1 to $1.5 \mathrm{~h}$. The formation of dioxazaluminium complex was monitored through the quantitative evolution of hydrogen by connecting the system to a gas burette.

Reduction of acetophenone using 7a: Acetophenone $(0.6 \mathrm{~mL}, 5 \mathrm{mmol})$ was added to a freshly prepared solution of $5 \mathrm{mmol}$ of dioxazaluminium complex and the resulting mixture was stirred for $1 \mathrm{~h}$ at $0^{\circ} \mathrm{C}$. The reaction was then quenched with dil. HCL. The reaction mixture was extracted with chloroform and washed with water. The chloroform layer was dried over anhydrous sodium sulphate and the solvent was removed under reduced pressure. Purification using CC with hexane: ethyl acetate (98:2) as eluant gave $0.54 \mathrm{~g}$ of the alcohol with $90 \%$ chemical yield and with $e e$ of $60 \%(\mathrm{~S})-(-) 1$-phenylethanol; $[\alpha]_{\mathrm{D}}{ }^{23}-24.7^{\circ}$

\section{References}

1. Grunden M.F.; McCleery D.G.; Wilson J.W. J. Chem. Soc. Perkin Trans., 1987, 1, 1857.

2. Hirao, A.; Itsuno, S.; Nakahama, S.; Yamazaki, J. J. Chem. Soc. Chem. Commun., 1981, 315.

3. Corey, E.J.; Link, J.O. Tett. Lett. 1990, 31, 601.

4. Steinhagen, H.; Helmchen, G. Angew. Chem. Int. Ed. Engl. 1996, 37, 2035.

5. Narasimhan, S.; Swarnalakshmi, S.; Balakumar, R.; Velmathi, S. Syn. Lett, 1998, 12, 1321.

6. Narasimhan, S.; Swarnalakshmi, S.; Balakumar, R.; Velmathi, S. Ind. J. Chem. (2001, in press)

7. Joshi, N.N.; Srebnik, M.; Brown, H.C. Tetrahedron, 1989, 30, 5551.

8. Corey E.J.; Raman K. Bakshi.; Saizo Shibatu. J. Am. Chem.. Soc., 1987, 109, 5551.

9. Aldrich, Catalog Handbook of Fine Chemicals 2000

10. Chiral Auxiliaries and Ligands in Asymmetric Synthesis Seyden- Penne, J. ed.; John Wiley \& Sons Inc: New York, 1995; Chapter 6. pp. 209.

Sample Availability: $100 \mathrm{mg}$ of compounds $\mathbf{1}$ and $\mathbf{4}$ are available from MDPI.

(C) 2001 by MDPI (http://www.mdpi.org). Reproduction is permitted for noncommercial purposes. 